\title{
DESIGN OF WIDE-FLANGE STAINLESS STEEL SECTIONS
}

\author{
M. Lecce ${ }^{1}$ and K.J.R. Rasmussen ${ }^{2}$ \\ ${ }^{1}$ Post Doctoral Fellow, Department of Civil Engineering, University of Toronto, \\ Toronto, Ontario, Canada, M5S 1 A4 \\ Tel: +1-416-978-3097,Fax: +1=416-978-6813,E-mail: mlecce@ecf.utoronto.ca \\ ${ }^{2}$ Professor, School of Civil Engineering, University of Sydney, \\ Sydney, New South Wales, NSW 2006, Australia \\ Tel: +61 29351 2125, Fax: +61 29351 3343,E-mail: k.rasmussen@civil.usyd.edu.au
}

\begin{abstract}
This paper describes a design procedure proposed to determine the moment capacities for the distortional and local buckling of wide-flange stainless steel sections influenced by flange curling. Experimental tests and theoretical analysis, conducted by the authors, of commercially available wide-flange stainless steel sections in pure bending have shown that flange-curling, where the wide-flange cross-section moves towards the neutral axis, reduces the cross-sectional section modulus, produces nonlinear stress distributions and increases the critical elastic buckling stresses. For the sections investigated, the section modulus is reduced by approximately $6 \%$ to $16.9 \%$, while the critical elastic buckling stress is increased by a factor of 1.10 to 3.41. Overall, it was found that flange curling produced a net increase of up to $10.6 \%$ for the distortional buckling moment capacity but a net decrease of up to $12.2 \%$ for the local buckling moment capacity. Based on this data, it is recommended that the effects of flange curling should be ignored for distortional buckling but that it would be necessary to consider them for local buckling. This paper investigates whether the recently proposed Direct Strength Method (DSM) for the distortional buckling of stainless steel sections developed by Lecce and Rasmussen [1], the Winter curve for local buckling, and the North American Specification for the Design of Cold-Formed Steel Structural Members [2] DSM formulations for cold-formed carbon steel are applicable to wide-flange stainless steel sections in bending. It is concluded that the recently proposed DSM for stainless steel sections in compression can also be used, as presented herein, for wide-flange stainless steel sections in bending.
\end{abstract}

Keywords: Stainless steel, direct strength method, pure bending, local buckling, distortional buckling, flange curling, section modulus

\section{INTRODUCTION}

A recent experimental investigation [3] was conducted on the distortional and local buckling of two commercially available wide-flange ferritic stainless steel sections named Monoclad and Megaclad. The wide-flange width-to-thickness ratios of the two sections are 217 and 328, respectively. The wide-flange roof sections were subject to pure bending and were oriented in the test rig so that the wide flange was either in compression or tension. Figure 1 shows the top view of an experimental test of the Megaclad section where the wide flange is in compression.

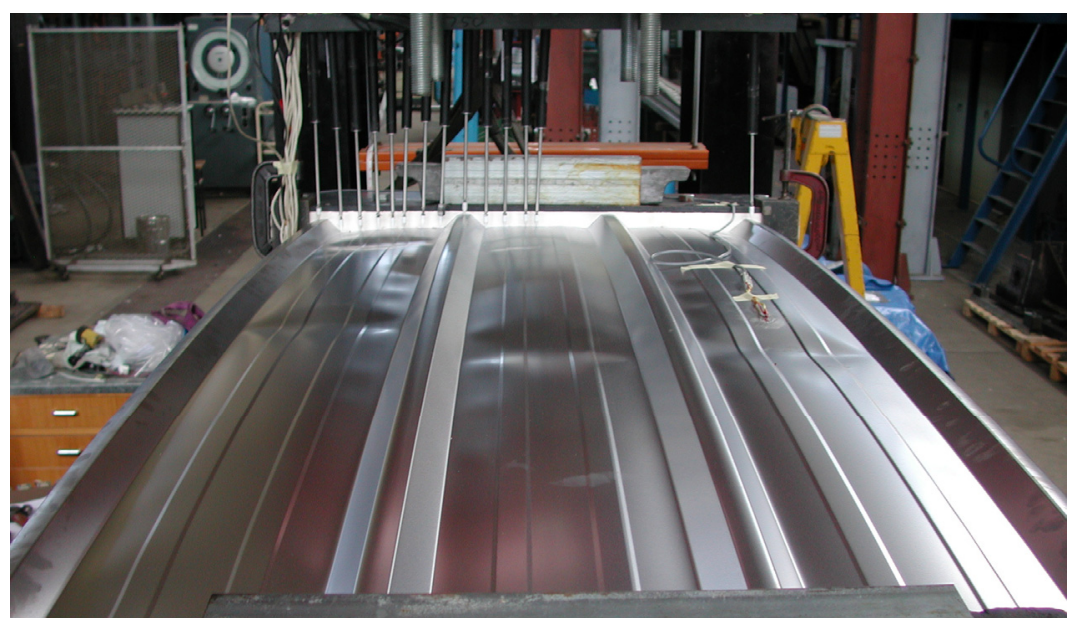

Figure 1. Megaclad Experimental Test 
A total of nine tests were conducted and all specimens showed evidence of flange curling. Flange curling is the tendency of the wide-flange of a thin walled section to shift towards the neutral axis when subject to bending and can occur when the wide-flange is in either tension or compression. As the wide flange moves towards the neutral axis, the cross-sectional geometry changes, the stress distribution becomes nonlinear, and the critical elastic buckling stress becomes altered. To gain a better understanding of this phenomenon and to quantitatively assess the deformations and associated flange stresses, Lecce and Rasmussen [4,5] developed a nonlinear flange curling model to theoretically capture the changing geometric and loading conditions. The theoretical analysis of the wide-flange section stresses show that the stresses vary nonlinearly from the centre-pan to the web-flange junction, and that the nonlinearity becomes more severe for more slender sections. A full detailed report can be found in $[4,5]$.

The lack of available literature on the effects of flange curling and, in particular, their influence on the distortional and local buckling failure modes was the motivation behind this research. Furthermore, any limited literature that is available is based on tests of cold-formed carbon steel sections. The most relevant research was initiated by Winter [6] who proposed an equation to evaluate the flange curling deformations:

$u_{m}=2 \frac{b_{s}^{4}}{t^{2}}\left(\frac{M}{E I}\right)^{2} y$

$M=\frac{I \sigma_{a}}{y}$

$q=\left(\frac{M}{I}\right)^{2} \frac{y t}{E}$

where $u_{m}$ is the deformation, $M$ is the applied moment, $y$ is the distance from the wide-flange to the neutral axis, $I$ is the moment of inertia, $q$ is a constant, uniform applied load causing flange curling, $b_{s}$ is half of the wide-flange width (or full width of the wide-flange if the section is cantilevered), $t$ is the section thickness, $\sigma_{a}$ is the average stress in the flange determined by engineering beam theory, and $E$ is the material modulus of elasticity. The constant " 2 " in Eq. 1 is an "average" of the theoretical values of 1.37 and 2.28 which correspond to idealized models where the flange curling deflections resemble that of a cantilevered, fixed-end beam (e.g., flange of an I-beam) and a simply supported beam (e.g., wide-flange simply supported by webs), respectively. The symbols $M, \sigma_{a}$ and $q$ in relation to a wide-flange section are depicted in Figure 2, (note the subscript " $a$ " on $\sigma \quad a$ has been dropped). In Figure 2 the symbol $r_{x}$ is the radius of curvature of the bent plate (see Section A-A in Figure 2).

Bernard et al. $[7,8]$ examined the phenomenon of flange curling of thin walled roof sections and developed equations for maximum deflection taking into account different wide-flange end conditions provided by the section webs. Bernard et al. [7, 8] found that the best estimate of flange curling deformations (when compared to experimental results) was obtained when the true boundary conditions were represented, which are specific to the cross-section and connection details of the roof sections tested. 

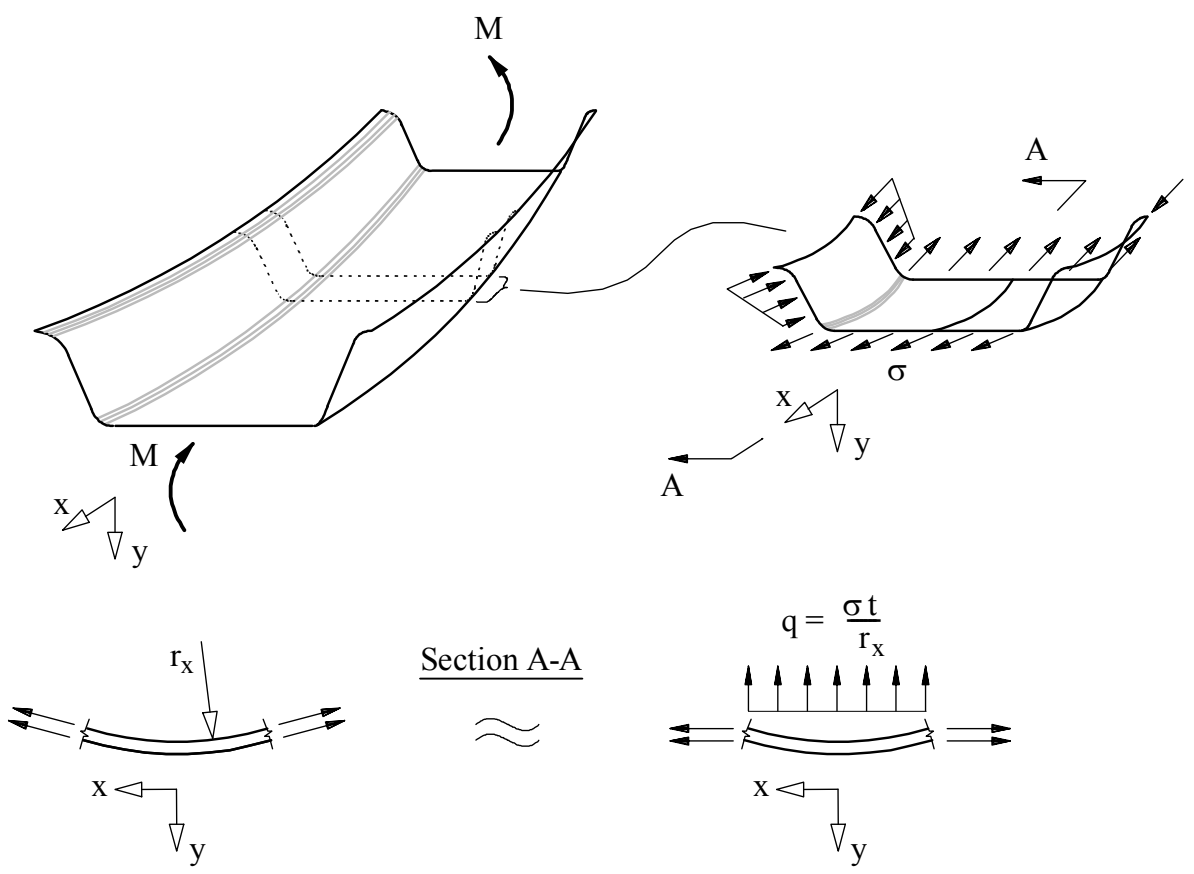

Figure 2. Flange Curling Stress Due to Applied Moment on a Wide-Flange Section

Nevertheless, the equations developed by Winter [6] and Bernard et al. [7] were developed based on the assumption that flange curling deformations were sufficiently small so that the stress $\left(\begin{array}{ll}\sigma & a\end{array}\right)$ causing flange curling remains uniform and that the cross-section properties including the first and second moment of area remains constant. With respect to the design of wide-flange sections, Bernard et al. [8] evaluated various design models for the distortional and/or local buckling modes and considered the interaction of local and distortional buckling but excluded the effects of flange curling.

The most recent research on wide-flange sections relevant to the research presented herein is that conducted by Davies and Chiu [9] who investigated both experimentally and numerically the behaviour of wide-flange, double-lip C-sections loaded in pure bending. The sections were used for double-skin "cassette" construction, and both foam-filled and non-filled sections were investigated. Davies and Chiu [9] suggest that if the wide flange is in tension, flange curling is not significant and if it is in compression, stresses which cause flange curling are "largely dissipated" once local buckling occurs. They also suggest that, for partially stiffened flange elements, the amount of flange curling can become significant but the magnitude can be estimated by considering the in-plane effective stress distribution.

Current guidelines in the Australian Standard/New Zealand Standard (AS/NZS) 4673 [10] for cold-formed stainless steel sections and the Direct Strength Method available in Appendix 1 of the North American Specification for the Design of Cold-Formed Steel Structural Members [2] (henceforth referred to as the NAS Appendix 1) for cold-formed carbon steel do not consider flange curling in the determination of ultimate moment capacity. The results of the experimental and theoretical investigations $[3,5,11]$ are used in this paper for the assessment of design equations for moment capacity of wide-flange stainless steel sections. The current Direct Strength Method (DSM) formulations presented in the current NAS Appendix 1 [2], the DSM proposed for distortional buckling of stainless steel sections [1] and the Winter curve for local buckling are considered in the assessment. 


\section{FLANGE CURLING AND CRITICAL ELASTIC BUCKLING STRESS}

The Direct Strength Method uses the critical elastic buckling stress (distortional buckling or local buckling), determined by rational analysis, and gross cross-sectional properties to evaluate the design strength. The ThinWall [12] finite strip elastic buckling analysis program was used to determine the gross cross-section properties and the critical elastic buckling stresses of the two wide-flanged sections, Monoclad and Megaclad, used in this study. Two sets of analyses were considered: one where the cross-section geometry was unaltered (or unaffected by flange curling); another where the theoretical flange curling displacements of the wide-flange were included in the cross-section geometry. The theoretical flange curling deformations, $u_{m}$, determined from a nonlinear flange curling model, are those which correspond to the mid-pan deformation at the experimental ultimate moment [5]. Therefore, the two sets of analyses provided critical elastic buckling stresses for the original cross-section and for a modified cross-section. The ThinWall program was used to calculate the section properties including the distance to the neutral axis, $y$, the second moment of area, $I$, gross section modulus, $Z$, section modulus to the extreme compression fibre, $Z_{f}$, and critical distortional or local elastic buckling stress, $f_{c r, d}$ and $f_{c r, l}$ respectively. These values are provided in Table 1, where those based on a modified cross-section are given the subscript " $m$ ".

Table 1. Original and Modified Geometric Properties and Critical Buckling Stresses

\begin{tabular}{|c|c|c|c|c|c|c|c|c|c|c|c|c|c|c|c|}
\hline \multirow[b]{2}{*}{ Section } & \multirow[b]{2}{*}{ Orientation } & & \multicolumn{5}{|c|}{$\begin{array}{c}\text { Original Properties and Stresses } \\
\text { (ThinWall) }\end{array}$} & \multirow{2}{*}{$\begin{array}{c}\begin{array}{c}\text { Max. } \\
\text { Disp. } \\
\text { (Maple) }\end{array} \\
u_{m} \\
\mathrm{~mm} \\
\end{array}$} & \multicolumn{5}{|c|}{$\begin{array}{l}\text { Modified Properties and Stresses } \\
\text { (ThinWall) }\end{array}$} & \multicolumn{2}{|c|}{ Comparison } \\
\hline & & $\begin{array}{c}M_{u, a v g} \\
\mathrm{Nm}\end{array}$ & $\begin{array}{c}y \\
\mathrm{~mm}\end{array}$ & $\begin{array}{c}I \\
\mathrm{~mm}^{4} \\
\end{array}$ & $\begin{array}{c}Z \\
\mathrm{~mm}^{3} \\
\end{array}$ & \begin{tabular}{|c|}
$Z_{f}$ \\
$\mathrm{~mm}^{3}$ \\
\end{tabular} & $\begin{array}{c}f_{c r, d} \text { or } \\
f_{c r, l} \\
\mathrm{MPa}\end{array}$ & & $\begin{array}{l}y_{m} \\
\mathrm{~mm}\end{array}$ & $\begin{array}{c}I_{m} \\
\mathrm{~mm}^{4} \\
\end{array}$ & $\begin{array}{c}Z_{m} \\
\mathrm{~mm}^{3} \\
\end{array}$ & $\begin{array}{l}Z_{f m} \\
\mathrm{~mm}^{3} \\
\end{array}$ & $\begin{array}{c}f_{c r, d m} \text { or } \\
f_{c r, l m} \\
\mathrm{MPa}\end{array}$ & $Z_{m} / Z$ & $f_{c r, m} / f_{c r}$ \\
\hline & & & 8.07 & 56980 & 2859 & 7062 & & 1.70 & 8.61 & 52920 & 2729 & 6144 & 422 & 0.955 & \\
\hline Mono & & 1150 & 8.07 & 56980 & 2859 & 2859 & 1371 & 3.11 & 9.06 & 49840 & 2632 & 2632 & 1509 & 0.921 & 1.101 \\
\hline Mega & WFC & 694 & 6.47 & 43800 & 2243 & 6768 & 104 & 6.91 & 8.98 & 31830 & 1871 & 3543 & 355 & 0.834 & 3.413 \\
\hline Mega & WFT & 740 & 6.47 & 43800 & 2243 & 2243 & 671 & 7.40 & 9.21 & 31210 & 1858 & 1858 & 824 & 0.828 & 1.228 \\
\hline
\end{tabular}

The stress distributions obtained from the critical elastic buckling analysis are depicted in Figures $3 \mathrm{a}$ and $3 \mathrm{~b}$ for the Monoclad and Megaclad sections, respectively. Clearly those distributions for the modified cross-sections decrease toward the centre of the flange and this decrease is greater for the more slender Megaclad section. Figures 4 and 5 show the critical buckling stress versus half-wavelength for the original (solid line) and modified cross-sections (dotted line) for the distortional (wide flange in compression, WFC) and local (wide flange in tension, WFT) buckling modes of Monoclad sections and Megaclad sections, respectively. The minimum buckling stresses are highlighted by a diamond-shape data point.

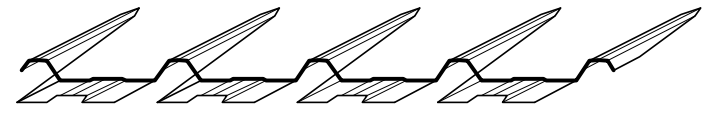

Original cross-section

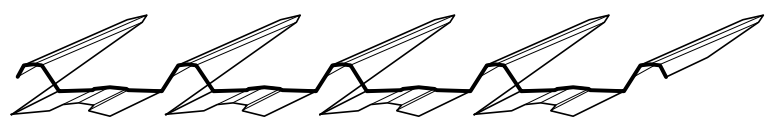

Modified cross-section

(a) Monoclad sections

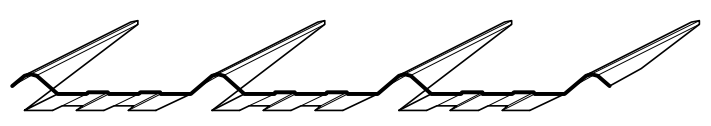

Original cross-section

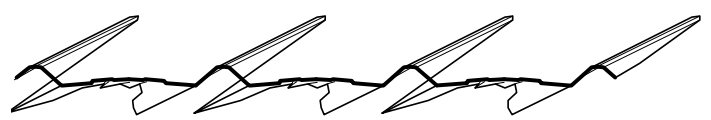

Modified cross-section

(b) Megaclad sections

Figure 3. Stress Distributions 

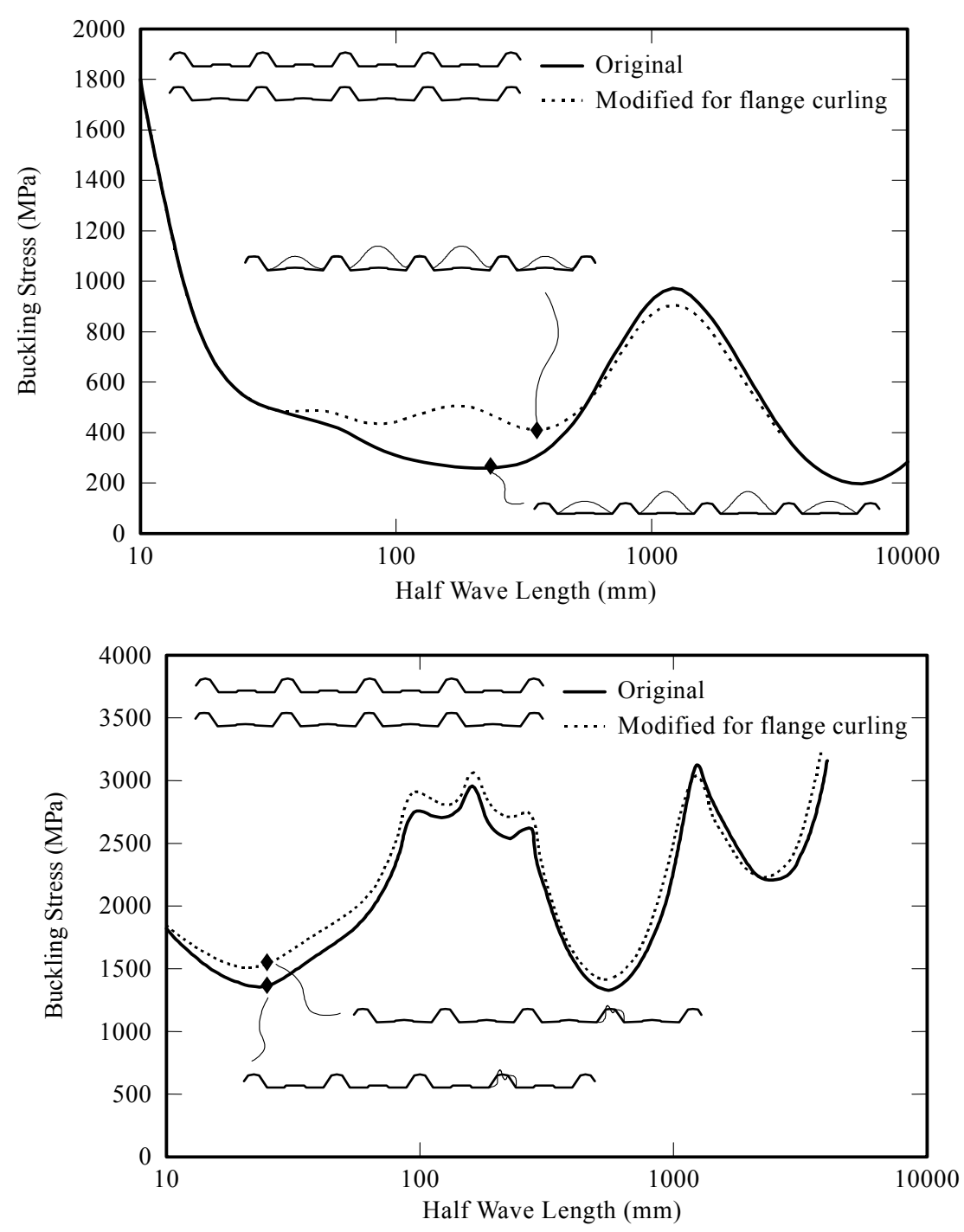

Figure 4. Elastic Buckling Analysis: Monoclad WFC (top); WFT (bottom)

When the wide flange is in compression, distortional buckling is the critical mode whereas when the wide flange is in tension, local buckling of the web/short flange is the critical buckling mode, and this is true irrespective of the influence of flange curling. As shown in Table 1, the modified cross-sections result in an increase in critical buckling stress. The ratio of the critical buckling stress of the modified section to that of the unaltered section $\left(f_{c r, m} / f_{c r}\right)$ ranges from 1.10 to 3.41. In the case of distortional buckling, the half-wavelengths associated with the critical stress are also increased. These effects are the result of the cylindrical shape of the wide-flange produced by flange curling which stiffens the cross-section against local and distortional modes of buckling.

If one examines the results of Table 1, it is clear that the increase in critical buckling stress is greater for the distortional buckling critical sections (WFC) than it is for the local buckling critical sections (WFT) and, although flange curling causes a decrease in the section modulus, the decrease (see the ratio of $Z_{m} / Z$ in Table 1) is greater for the local buckling critical sections. 

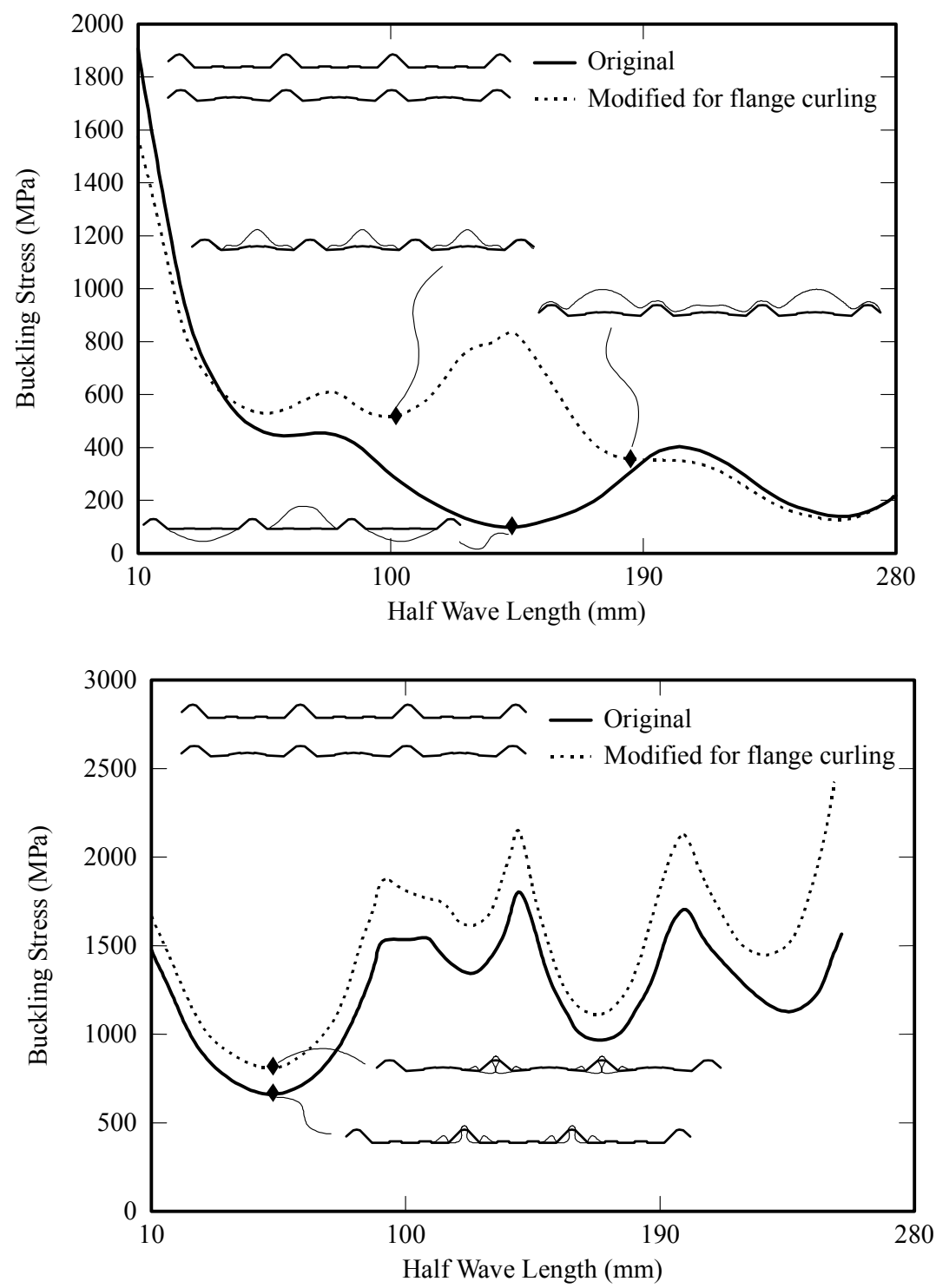

Figure 5. Elastic Buckling Analysis: Megaclad WFC(top) ; WFT (bottom)

Furthermore, flange curling deformations have a much greater influence on the more slender Megaclad section. The distortional and local critical buckling stresses for the Megaclad section is increased by a factor of 3.41 and 1.23 respectively whereas for the Monoclad section, the stresses are increased by a factor of 1.53 and 1.10 respectively. Although flange curling increases the critical buckling stress, the section modulus is reduced and this compromises the moment capacity. The section modulus is reduced by an average of $6 \%$ for the Monoclad section and $16.9 \%$ for the Megaclad section, again showing that flange curling has a greater influence on the more slender section. In any case, when considering the moment capacity, the net effect of increased critical buckling stress and decreased section modulus needs to be considered.

\section{DIRECT STRENGTH METHOD TO DETERMINE MOMENT CAPACITY}

The direct strength method provided in Appendix 1 of the North American Specification for the Design of Cold-Formed Steel Structural Members [2] for cold-formed carbon steel is considered for the design of stainless steel roof sections. Furthermore, the well-known Winter curve for local buckling and the proposed distortional buckling strength curve for stainless steel sections in 
compression [1] are also considered in the design evaluations. Note that research [13] has shown that the Winter curve provides accurate design strength predictions for the local buckling mode for stainless steel sections. The equations used in the DSM evaluations to determine moment capacity are as follows:

$$
\begin{aligned}
& \lambda_{d}=\sqrt{\frac{M_{y}}{M_{c r, d}}} \\
& M_{c r, d}=f_{c r, d} Z_{f} \\
& \lambda_{l}=\sqrt{\frac{M_{y}}{M_{c r, l}}} \\
& M_{c r, l}=f_{c r, l} Z_{f} \\
& M_{y}=f_{y} Z
\end{aligned}
$$

where, $\lambda$ is slenderness, $M_{c r}$ is the critical buckling moment, $M_{y}$ is the yield moment, $Z$ is the section modulus and $Z_{f}$ is the section modulus calculated at the extreme compression fibre. The subscript " $d$ " refers to distortional buckling and " $l$ " to local buckling. ( $M_{y}$ and $f_{y}$ are design yield moment and design yield stress, respectively, but are replaced by $M_{0.2}$ and $\sigma_{0.2}$, where $\sigma_{0.2}$ is the equivalent yield stress used in the design of stainless steels and other metals exhibiting gradual yielding). The design strength curves used in the evaluations are as follows:

Distortional Buckling, NAS Appendix 1 [2]:

$$
M_{n, d}=M_{y}\left[\frac{1}{\lambda_{d}}-\frac{0.22}{\lambda_{d}{ }^{2}}\right] \leq M_{y}
$$

Distortional Buckling, based on Lecce and Rasmussen [1] for ferritic stainless steel:

$$
M_{n, d}=M_{y}\left[\frac{0.90}{\lambda_{d}^{1.1}}-\frac{0.20}{\lambda_{d}^{2.2}}\right] \leq M_{y}
$$

Local Buckling, NAS Appendix 1 [2]:

$$
M_{n, l}=M_{y}\left[\frac{1}{\lambda_{l}^{0.8}}-\frac{0.15}{\lambda_{l}^{1.6}}\right] \leq M_{y}
$$

Local Buckling, Winter curve:

$$
M_{n, l}=M_{y}\left[\frac{1}{\lambda_{l}}-\frac{0.22}{\lambda_{l}^{2}}\right] \leq M_{y}
$$

In Eqs. 9-12, $M_{n}$ is the design moment capacity and the subscripts " $d$ " and "l" represent distortional 
and local buckling, respectively.

The DSM evaluations using the distortional buckling strength curves given by the NAS Appendix 1 [2] for carbon steel (Eq. 9) and Lecce and Rasmussen [1] for stainless steel (Eq. 10) are presented in Tables 2 and 3. The evaluations given in Table 2 are based on original cross-sectional properties and associated critical buckling stresses whereas those given in Table 3 account for flange curling and are based on modified geometric properties and associated critical buckling stresses.

Table 2. Distortional Buckling Strength Evaluations Based on Original Properties

\begin{tabular}{|c|c|c|c|c|c|c|c|c|c|c|c|c|}
\hline & Test & \multicolumn{7}{|c|}{$\begin{array}{l}\text { Values used in Distortional Buckling } \\
\text { Strength Calculations }\end{array}$} & \multicolumn{2}{|c|}{$\begin{array}{l}\text { NAS Appendix 1, } \\
\text { Eq. (9) }\end{array}$} & \multicolumn{2}{|c|}{$\begin{array}{c}\text { Lecce and } \\
\text { Rasmussen, Eq. (10) }\end{array}$} \\
\hline Test ID & $\begin{array}{l}M_{u} \\
\mathbf{N m}\end{array}$ & $\begin{array}{c}Z \\
\mathrm{~mm}^{3}\end{array}$ & $\begin{array}{l}\sigma_{0.2} \\
\mathrm{MPa}\end{array}$ & $\begin{array}{r}M_{0.2} \\
\mathrm{Nm}\end{array}$ & $\begin{array}{c}Z_{f} \\
\mathrm{~mm}^{3}\end{array}$ & $\begin{array}{l}f_{c r, d} \\
\mathrm{MPa}\end{array}$ & $\begin{array}{c}M_{c r, d} \\
\mathrm{Nm}\end{array}$ & $\lambda_{d}$ & $\begin{array}{c}M_{n, d} \\
\mathrm{Nm}\end{array}$ & $M_{u} / M_{n, d}$ & $\begin{array}{c}M_{n, d} \\
\mathrm{Nm}\end{array}$ & $M_{u} / M_{n, d}$ \\
\hline $\begin{array}{l}\text { MONO1 } \\
\text { MONO2 } \\
\text { MONO3 }\end{array}$ & $\begin{array}{l}878 \\
853 \\
845\end{array}$ & 2859 & 346 & 989 & 7062 & 275 & 1941 & 0.71 & 959 & $\begin{array}{l}0.916 \\
0.890 \\
0.881\end{array}$ & 875 & $\begin{array}{l}1.004 \\
0.975 \\
0.966\end{array}$ \\
\hline $\begin{array}{l}\text { MEGA1 } \\
\text { MEGA2 }\end{array}$ & $\begin{array}{l}679 \\
707\end{array}$ & 2243 & 388 & 870 & 6768 & 104 & 704 & 1.11 & 628 & $\begin{array}{l}1.082 \\
1.126\end{array}$ & 559 & $\begin{array}{l}1.214 \\
1.264 \\
\end{array}$ \\
\hline & & & & & & & & & $\begin{array}{c}\text { mean } \\
s t d v \\
\text { cov }\end{array}$ & $\begin{array}{c}0.979 \\
0.1157 \\
0.1182\end{array}$ & & $\begin{array}{c}1.085 \\
0.1428 \\
0.1317\end{array}$ \\
\hline
\end{tabular}

Table 3. Distortional Buckling Strength Evaluations Based on Modified Properties

\begin{tabular}{c|c|c|c|c|c|c|c|c|c|c|c|c|}
\hline & Test
\end{tabular}

As shown in Table 2, the NAS Appendix 1 [2] Eq. 9 provides reasonable moment capacities $\left(M_{n, d}\right)$ for the more slender $\left(\lambda_{d}=1.11\right)$ Megaclad section but is unconservative for the stockier Monoclad section $\left(\lambda_{d}=0.71\right)$. The NAS Appendix 1 [2] for cold-formed carbon steel does not account for the stainless steel material nonlinearity and this partly explains why the Monoclad strength ratios $\left(M_{u} / M_{n, d}\right)$ are less than unity. The distortional buckling DSM curve developed for ferritic alloys given by Eq. 10 offers an improvement to Eq. 9 giving a mean test to predicted strength ratio $M_{u} / M_{n, d}$ of 1.085 compared with the mean $M_{u} / M_{n, d}=0.979$.

If flange curling effects are taken into account in the distortional buckling strength calculations, as shown in Table 3, then more consistent, but not necessarily more conservative, results are obtained. The coefficients of variation (COV) given in Table $3(0.0672,0.0963)$ are significantly less than those given in Table $2(0.1182,0.1317)$. Also, it is clear from the results of Tables 2 and 3 that flange curling effects have the greatest impact on the design moment capacities of the more slender 
Megaclad section. This is unsurprising since this section has been shown to have the greatest enhancement in distortional buckling stress and the greatest decrease in section modulus (see Table 1). The average $M_{u} / M_{n, d}$ ratio has decreased from an average of 1.239 (Table 2) to an average of 1.121 (Table 3). Therefore, the combination of increased critical buckling stress (and decreased slenderness) and reduced section modulus results in an average net increase in predicted capacity of $10.6 \%$. The discrepancy between the Monoclad and Megaclad evaluations can be explained by the sections' sensitivity to flange curling.

Tables 4 and 5 gives the local buckling strength evaluations using the NAS Appendix 1 [2] (Eq. 11) and the Winter curve (Eq. 12). The evaluations given in Table 4 are based on original cross-sectional properties and associated critical buckling stresses whereas those given in Table 5 account for flange curling and are based on modified geometric properties and associated critical buckling stresses.

Table 4. Local Buckling Strength Calculations Based on Original Properties

\begin{tabular}{|c|c|c|c|c|c|c|c|c|c|c|c|c|}
\hline & Test & \multicolumn{7}{|c|}{$\begin{array}{l}\text { Values used in Local Buckling Strength } \\
\text { Calculations }\end{array}$} & \multicolumn{2}{|c|}{$\begin{array}{l}\text { NAS Appendix } 1 \\
\text { Eq. (11) }\end{array}$} & \multicolumn{2}{|c|}{ Winter, Eq. (12) } \\
\hline Test ID & $\begin{array}{l}M_{u} \\
\mathbf{N m}\end{array}$ & $\begin{array}{c}Z \\
\mathrm{~mm}^{3}\end{array}$ & $\begin{array}{c}\sigma_{0.2} \\
\mathrm{MPa}\end{array}$ & $\begin{array}{r}M_{0.2} \\
\mathrm{Nm}\end{array}$ & $\begin{array}{c}Z_{f} \\
\mathrm{~mm}^{3}\end{array}$ & $\begin{array}{l}f_{c r, l} \\
\mathrm{MPa}\end{array}$ & $\begin{array}{c}M_{c r, l} \\
\mathrm{Nm}\end{array}$ & $\lambda_{l}$ & $\begin{array}{l}M_{n, l} \\
\mathrm{Nm}\end{array}$ & $M_{u} / M_{n, l}$ & $\begin{array}{c}M_{n, l} \\
\mathrm{Nm}\end{array}$ & $M_{u} / M_{n, l}$ \\
\hline $\begin{array}{l}\text { MONO7 } \\
\text { MONO8 }\end{array}$ & $\begin{array}{l}1179 \\
1121 \\
\end{array}$ & 2859 & 346 & 989 & 2859 & 1371 & 3920 & 0.50 & 989 & $\begin{array}{l}1.192 \\
1.133\end{array}$ & 989 & $\begin{array}{l}1.192 \\
1.133\end{array}$ \\
\hline $\begin{array}{l}\text { MEGA3 } \\
\text { MEGA4 }\end{array}$ & $\begin{array}{l}726 \\
748\end{array}$ & 2243 & 388 & 870 & 2243 & 671 & 1506 & 0.76 & 870 & $\begin{array}{l}0.834 \\
0.859\end{array}$ & 814 & $\begin{array}{l}0.892 \\
0.919\end{array}$ \\
\hline & & & & & & & & & $\begin{array}{c}\text { mean } \\
\text { stdv } \\
\text { cov }\end{array}$ & $\begin{array}{c}1.005 \\
0.1841 \\
0.1833\end{array}$ & & $\begin{array}{c}1.034 \\
0.1505 \\
0.1455\end{array}$ \\
\hline
\end{tabular}

Table 5. Local Buckling Strength Evaluations Based on Modified Properties

\begin{tabular}{|c|c|c|c|c|c|c|c|c|c|c|c|c|}
\hline & Test & \multicolumn{7}{|c|}{$\begin{array}{l}\text { Values used in Local Buckling Strength } \\
\text { Calculations }\end{array}$} & \multicolumn{2}{|c|}{$\begin{array}{l}\text { NAS Appendix } 1 \\
\text { Eq. (11) }\end{array}$} & \multicolumn{2}{|c|}{ Winter Eq. (12) } \\
\hline Test ID & $\begin{array}{l}M_{u} \\
\text { Nm }\end{array}$ & $\begin{array}{l}Z_{m} \\
\mathrm{~mm}^{3} \\
\end{array}$ & $\begin{array}{l}\sigma_{0.2} \\
\mathrm{MPa}\end{array}$ & $\begin{array}{c}M_{0.2, m} \\
\mathrm{Nm}\end{array}$ & $\begin{array}{l}Z_{f, m} \\
\mathrm{~mm}^{3} \\
\end{array}$ & $\begin{array}{l}f_{c r, l m} \\
\mathrm{MPa}\end{array}$ & $\begin{array}{c}M_{c r, l m} \\
\mathrm{Nm}\end{array}$ & $\lambda_{l m}$ & $\begin{array}{c}M_{n, l m} \\
\mathrm{Nm}\end{array}$ & $M_{u} / M_{n, l m}$ & $\begin{array}{c}M_{n, l m} \\
\mathrm{Nm}\end{array}$ & $M_{u} / M_{n, l m}$ \\
\hline $\begin{array}{l}\text { MONO7 } \\
\text { MONO8 }\end{array}$ & $\begin{array}{l}1179 \\
1121 \\
\end{array}$ & 2632 & 346 & 911 & 2632 & 1509 & 3972 & 0.48 & 911 & $\begin{array}{l}1.295 \\
1.231\end{array}$ & 911 & $\begin{array}{l}1.295 \\
1.231\end{array}$ \\
\hline $\begin{array}{l}\text { MEGA3 } \\
\text { MEGA4 }\end{array}$ & $\begin{array}{l}726 \\
748\end{array}$ & 1858 & 388 & 721 & 1858 & 824 & 1532 & 0.69 & 721 & $\begin{array}{l}1.007 \\
1.038\end{array}$ & 714 & $\begin{array}{l}1.017 \\
1.048\end{array}$ \\
\hline & & & & & & & & & $\begin{array}{c}\text { mean } \\
\text { stdv } \\
\text { cov }\end{array}$ & $\begin{array}{c}1.143 \\
0.1418 \\
0.1241 \\
\end{array}$ & & $\begin{array}{c}1.148 \\
0.1360 \\
0.1185 \\
\end{array}$ \\
\hline
\end{tabular}

The predicted capacity given in Table 4 for both Monoclad and Megaclad sections is governed by the yield moment (i.e., $M_{n, l}=M_{0.2}$ ) except for the Winter evaluation for the more slender Megaclad section. The Winter curve given by Eq. 12 is marginally more conservative than Eq. 11 and this translates to a marginal improvement in the mean test to predicted strength ratio $\left(M_{u} / M_{n, l}=1.005\right.$ given by Eq. 11 compared with $M_{u} / M_{n, l}=1.034$ given by Eq. 12).

If flange curling is considered in the local buckling strength evaluation, as shown in Table 5, then there is an improvement in the predicted moment capacities. Flange curling has the effect of decreasing the section modulus $\left(Z\right.$ ) and since $M_{0.2}=\sigma_{0.2} Z$ (or $M_{y}=f_{y} Z$ ), the moment at which yielding occurs also decreases. The $M_{u} / M_{n, l}$ ratio for the Monoclad section changes from an average of 
1.163 (Table 4) to an average of 1.263 (Table 5) and therefore the design evaluations become even more conservative if flange curling is taken into account. This is primarily because the section is fully effective ( $\lambda_{l}=0.50$ and $\left.\lambda_{l m}=0.48\right)$, and hence parts of the cross-section are capable of reaching stresses higher than the $0.2 \%$ proof stress. Referring to Table 5 , the mean test to predicted strength ratios $M_{u} / M_{n, l m}$ given by Eq. 11 and Eq. 12 are 1.143 and 1.148, respectively.

Comparing the results of the Megaclad to Monoclad sections in Tables 4 and 5, it is clear that the improvement in strength predictions is more significant for the Megaclad section. That is, the predicted local buckling capacity $\left(M_{n, l}\right)$ is reduced by $12.2 \%$ if modified properties are considered, and the $M_{u} / M_{n, l}$ ratio increases from an average of 0.906 to 1.033 (using the Winter curve evaluation).

Overall, if distortional buckling is considered (wide flange in compression) then the flange curling effects produce a net increase in the predicted capacities. However, if local buckling is considered (wide flange in tension) then the flange curling effects produce a net decrease in the predicted capacity. Furthermore, the evaluations based on Eq. 10 for distortional buckling and Eq. 12 for local buckling provide more conservative results than the NAS Appendix 1 [2] predictions and would be more suitable for the design of stainless steel sections.

Given the present data, it would be prudent to ignore the effects of flange curling to determine the moment capacity for distortional buckling but include them to determine the moment capacity for the local buckling mode. As shown in Lecce and Rasmussen [5], flange curling deformations can be determined sufficiently accurate from an analysis based on the original cross-section geometry, (while the applied stress distribution cannot). A suitable design procedure for sections with the wide flange in tension can therefore be suggested as follows:

- Determine the design moment $\left(M_{n, l}\right)$ on the basis of the original cross-section geometry using the Direct Strength Method

- Determine the flange curling deformations at this moment, e.g. as per [5]

- Modify the cross-section geometry to account for flange curling deformations

- Determine the design moment capacity for the modified cross-section using the Direct Strength Method

It is recognized that these recommendations are based on relatively few results and more data are required to establish the geometric limits for which flange curling becomes sufficiently significant to adversely affect the capacity and the design procedure would have to be reassessed given more data. For the assessment presented here, it is reasonable to ignore the effects of flange curling for the stockier Monoclad section whether designing against local or distortional buckling, but the same simplification would not be appropriate for the Megaclad section. Finally, there is now an understanding of the flange-curling phenomenon, how it affects the distortional and local buckling behaviour and its impact on the design of stainless steel roof sections.

\section{CONCLUSIONS}

The results of elastic buckling analysis of wide-flange roof sections both ignoring and including flange curling deformations have been presented. Overall, an increase in elastic buckling stress results when flange curling deformations are included. For the sections investigated, the influence of flange curling is greater for the more slender Megaclad section, with a wide-flange width-to-thickness ratio of 328, and there is an increase in the critical elastic distortional buckling stress by a factor of 3.41 compared to that based on an analysis without flange curling considered. 
The critical elastic local buckling stress increased by a factor of 1.23 due to flange curling for the Megaclad section. Flange curling also has the effect of decreasing the section modulus, amounting to reductions of $6 \%$ and $16.9 \%$ for the Monoclad and Megaclad sections, respectively.

The assessment of design equations for the distortional and local buckling of roof sections subject to bending shows significant scatter in the results if flange curling effects are ignored. A marked decrease in the scatter of results can be achieved by including the effects of flange curling in the design. Given the present data, it is recommended that the effects of flange curling should be ignored in the prediction of distortional buckling moment capacity but that they should be included in the prediction of local buckling moment capacity. The proposed DSM for the distortional buckling of stainless steel sections, given by Eq. 10 (based on Lecce and Rasmussen [1]), and the Winter curve for local buckling, given by Eq. 12 (with modified properties and stresses to account for flange curling) are more suitable for predicting the moment capacities than the current NAS Appendix 1 [2] for cold-formed carbon steel.

\section{REFERENCES}

[1] Lecce, M., and Rasmussen, K.J.R., "Distortional Buckling of Cold-Formed Stainless Steel Sections: Finite Element Modeling and Design", Journal of Structural Engineering, 2006, Vol. 134, No. 4, pp. 505-514.

[2] AISI, "North American Specification for the Design of Cold-Formed Steel Structural Members", 2007, American Iron and Steel Institute, Washington, D.C.

[3] Lecce, M., and Rasmussen, K.J.R., "Experimental Investigation of Wide Flange Stainless Steel Sections in Bending", Proceedings of the $6^{\text {th }}$ International Conference on Steel and Aluminium Structures, Ed. R.G. Beale, Oxford, July 2007, pp. 1033-1040.

[4] Lecce, M., and Rasmussen, K.J.R., "Nonlinear Flange Curling of Wide-Flange Sections", Research Report No. 850, 2005, Department of Civil Engineering, University of Sydney, Sydney.

[5] Lecce, M., and Rasmussen, K.J.R., "Nonlinear Flange Curling in Wide Flange Sections", Journal of Constructional Steel Research, 2008, Vol. 64, No. 7-8, pp. 779-784.

[6] Winter, G., "Stress Distribution in and Equivalent Width of Flanges of Wide, Thin-Walled Steel Beams", NACA Technical Note, 1940 (784).

[7] Bernard, E.S., Bridge, R.Q., and Hancock, G.J., "Flange Curling in Profiled Steel Decks", Thin-Walled Structures, 1996, Vol. 25, No. 1, pp. 1-29.

[8] Bernard, E.S., Bridge, R.Q., and Hancock, G.J., "Design Methods for Profiled Steel Decks with Intermediate Stiffeners" Journal of Constructional Steel Research, 1996, Vol. 38, No. 1, pp. 61-88.

[9] Davies, J.M., and Chiu, R., "Flange Curling in Slender Sections" Proceedings of the 4th Specialty Conference on Cold-Formed Steel Structures, Ed. J. Loughlan, 2004. Loughborough, UK, IOP Publishing Ltd., pp. 39-55.

[10] AS/NZS 4673, "Cold-Formed Stainless Steel Structures", Australian Standard/New Zealand Standard 4673:2001, 2001, Standards Australia, Sydney, Australia.

[11] Lecce, M., and Rasmussen, K.J.R., "Experimental Investigation of Stainless Steel Roof Sections in Pure Bending", Research Report No.847, 2005, Department of Civil Engineering, University of Sydney, Sydney.

[12] Papangelis, J.P., and Hancock, G.J., "Computer Analysis of Thin-Walled Structural Members. Computers \& Structures”, 1995, Vol. 56, No. 1, pp. 157-176.

[13] Rasmussen, K.J.R., Burns, T., and Bezkorovainy, P., "Design of Stiffened Elements in Cold-Formed Stainless Steel Sections", Journal of Structural Engineering, 2004, Vol. 130, No. 11, pp. 1764-1771. 